\title{
Retrospective Investigation of Case Studies to Determine the Concurrent Malignancy Rate Associated with Microscopic Polyangiitis
}

\author{
Tomohiko Shibata ${ }^{1}$, Machiko Mizushima², Toshiko Shibata ${ }^{2}$, Yoshioki Yamasaki ${ }^{2}$, \\ Hiroko Nagafuchi², Hidehiro Yamada², and Shoichi Ozaki ${ }^{2}$
}

(Received for Publication: December 16, 2014)

\begin{abstract}
Introduction: This retrospective study investigated the concurrence rate and clinical characteristics of recently developed malignancies with microscopic polyangiitis (MPA).

Materials and Methods: The subjects included 42 Japanese MPA cases (16 males and 26 females) that had been newly admitted to the hospital. Recent occurrences of malignancy (defined as malignancies diagnosed upon admission and up to two years prior to admission) and the presence of organ lesions were evaluated. As a control, recent occurrences of malignancy in 126 patients with rheumatoid arthritis (RA) were evaluated in a similar manner.

Results: Recently developed malignancies occurred significantly more often in the MPA group (19.0\%) than in the RA group (6.3\%; odds ratio (OR), 3.47 [95\% CI, 1.21-9.93]; Fisher's exact test, $p=0.029$ ). All MPA-associated malignancies were solid cancers, and none were from hematopoietic origin. With regard to characterization of organ lesions, MPA cases with malignancies exhibited peripheral neuropathy significantly more often (75\% vs. 32.4\%; OR, 6.27; 95\% CI, 1.09-36.25; $p=0.045$ ) and glomerulonephritis less often (37.5\% vs. $82.4 \%$; OR, 0.13 ; 95\% CI, 0.02-0.69; $p=0.020)$ than MPA cases without malignancies. Skin lesions were observed in approximately $50 \%$ of cases, and there was no significant difference between MPA groups with and without malignancies $(26.5 \%$; OR, 2.78; 95\% CI, 0.57-12.51; $p$ value, 0.236$)$.
\end{abstract}

Conclusion: MPA coincided with malignancies at a higher ratio than did RA. Therefore, it is recommended that those admitted for MPA should be thoroughly screened for malignancies.

\section{Key words}

MPA, malignancy, concurrent, ANCA-associated vasculitis, organ

\section{Introduction}

Collagen disease and vasculitis often coincide with malignancies. In particular, $6 \%$ of dermatomyositis cases also presented with malignancy at the time of diagnosis ${ }^{1}$. Primary vasculitis, polyarteritis nodosa, anti-neutrophil cytoplasmic antibody (ANCA)associated vasculitis (AAV), and IgA vasculitis also frequently coincide with malignancies ${ }^{2-5}$. In cases of $\mathrm{AAV}$, immunosuppressants such as cyclophospha- mide are administered for treatment after diagnosis, and it is reported that malignancies develop more often in such cases than in the general population ${ }^{6-13)}$. This may suggest that immunosuppression treatment carries an inherent risk of increased cancer rates in those with AAV. However, because little is known about the occurrence rate of malignancies at the time of diagnosis and before the onset of AAV, the causal relationship between malignancy and AAV remains in question. In 2004, Pankhurst et al. ${ }^{3)}$ retrospectively

1 Division of Rheumatology, Department of Internal Medicine, St. Marianna University School of Medicine Yokohama Seibu Hospital

2 Division of Rheumatology and Allergy, Department of Internal Medicine, St. Marianna University School of Medicine 
investigated the history and occurrence rate of malignancies at the time of diagnosis in patients newly diagnosed with AAV and reported that malignancies occurred in $11.5 \%$ of microscopic polyangiitis (MPA) cases. MPA is one type of AAV, and it is known to develop after certain circumstances such as infection, drug administration, and malignancy ${ }^{6}$. To gain a better understanding of the coincidence of MPA and malignancy, we retrospectively investigated the occurrence of recent malignancies in MPA patients admitted to the hospital. We determined the concurrence rate of malignancies with MPA and evaluated the clinical characteristics defining MPA cases with malignancies.

\section{Materials and Methods}

The subjects included 42 Japanese MPA cases (16 males and 26 females) that were admitted to the St. Marianna University School of Medicine Hospital over a span of 58 months between April 1, 2008 and January 31,2012 . We surveyed all subjects who were admitted to the hospital during this period. In addition to newly developed MPA cases, those who had been previously diagnosed and had disease progression were included in the survey. The diagnosis of MPA was based on the definitions established by the Chapel Hill Consensus Conference ${ }^{14)}$ or on the diagnostic criteria of the Research Group of Intractable Vasculitis of the Ministry of Health, Labor and Welfare of Japan ${ }^{15)}$. The control subjects included 126 Japanese cases diagnosed with rheumatoid arthritis (RA) based on the American Rheumatism Association 1987 revised criteria for the classification of RA $^{16)}$. Control subjects were admitted to the hospital during the same time period and were age- and gender-matched with the MPA group.

"Recently developed malignancies" were defined as all malignancies diagnosed within the two years prior to and including the time of admission. At our hospital, the following examinations were routinely performed for exploration of malignancy in newly hospitalized cases with autoimmune diseases. Screening exams included chest radiograph, chest and abdominal computed tomography (CT), abdominal echography, upper gastrointestinal endoscopy, colonoscopy for patients with a positive fecal occult blood test, colposcopy for female patients, prostatespecific antigen for male patients, and a thyroid echo in the case of struma ${ }^{17)}$. In addition to these examinations, concurrence of malignancies was diagnosed by pathohistology. In cases of poor general conditions, not all of the above-mentioned tests could be performed. History of malignancies was determined from medical charts. The rates of recently developed malignancies concurrent with MPA and RA were determined and compared.

Using medical charts, we investigated organ lesions associated with MPA, positive rates of myeloperoxidase (MPO)-ANCA and proteinase-3 (PR-3)ANCA, and treatment history. Organ lesions in the MPA group were evaluated according to the following methods. Interstitial lung disease (ILD) was evaluated by chest $\mathrm{X}$-rays and high-resolution $\mathrm{CT}$ (HRCT), and radiologists diagnosed the disease when they detected interstitial shadows. When abnormal peripheral nerve conductivity was observed in addition to clinical findings of obvious sensory or motor nerve injury, peripheral neuropathy such as mononeuritis multiplex was diagnosed. Glomerular nephritis was diagnosed when urine contained blood and/or an unusually high amount of protein and when urinary sediments showed casts derived from glomeruli. Skin lesions were defined as present when the vasculitis was confirmed pathohistologically and when coupled with obvious vasculitis-derived purpura and ulcers by dermatologists. Arthritis was defined as positive by rheumatologists when joint tenderness and swelling were detected at one or more sites by rheumatologists. Characteristics of organ lesions were compared between MPA cases with and without recently developed malignancies.

This study was approved in advance by the ethics committee at St. Marianna University School of Medicine (approval No. 2527).

\section{Statistical analyses}

The statistical analyses were performed using SPSS Statistics, version 22.0 (SPSS Japan Inc., Tokyo, Japan). Age and disease duration are reported as mean \pm standard deviation (SD). Statistical significance was determined using Fisher's exact test, odds ratios [ORs], and 95\% confidence intervals [CIs]. Pvalues of less than 0.05 were considered significant.

\section{Results}

\section{Patient characteristics in the MPA group}

Table 1 shows the patient characteristics in the MPA group. The group comprised 42 MPA cases (16 males and 26 females) with an average age of 69.9 \pm 10.1 years upon admission to the hospital and with average disease duration of $16.0 \pm 27.6$ months. There were 13 cases with first-onset MPA, 13 that 
Table 1. Background of MPA Patients

\begin{tabular}{lr}
\hline & MPA $(\mathrm{n}=42)$ \\
\hline Female & $61.9 \%$ \\
Age: mean \pm SD (years) & $69.9 \pm 10.1$ \\
Disease duration: mean \pm SD (months) & $16 \pm 27.6$ \\
Organ involvement & \\
$\quad$ Glomerular nephritis & $31(73.8 \%)$ \\
$\quad$ Interstitial lung disease & $27(64.3 \%)$ \\
$\quad$ Arthritis & $18(42.9 \%)$ \\
$\quad$ Peripheral neuropathy & $17(40.5 \%)$ \\
Skin lesions & $13(31.0 \%)$ \\
ANCA positive & \\
$\quad$ MPO-ANCA & $39(92.9 \%)$ \\
PR3-ANCA & $1(2.4 \%)$ \\
\hline
\end{tabular}

were diagnosed 1-6 months before admission to the hospital, 7 that were diagnosed 7-24 months before hospitalization, and 9 in the chronic stage 25 months or longer before hospitalization.

With regard to organ lesions, glomerular nephritis was most frequently observed $(73.8 \%)$, followed by ILD $(64.3 \%)$, arthritis (42.9\%), peripheral neuropathy $(40.5 \%)$, and skin lesions (31\%). MPO-ANCA was positive in $92.9 \%$ of cases and PR-3 ANCA was positive only in $2.4 \%$ of cases.

\section{Characteristics of recently developed MPA cases with malignancies}

Table 2 shows characteristics of recently developed MPA cases with malignancies. Concurrent malignancies were observed in eight cases (four males and four females; 19.0\%). In cases with malignancies, the average age was $72.9 \pm 5.4$ years upon admission and the average disease duration of MPA was $10.6 \pm 19.1$ months. Malignancies included liver cancer in two cases, and one case each of lung cancer, colon cancer, skin basal cell carcinoma, rectal cancer, duodenal cancer, breast cancer, and cervical cancer. Among those, one case developed both breast and liver cancer. Malignancies were diagnosed two years prior to admission in four cases and upon admission in four cases.

With regard to organ lesions in cases with malignancies, peripheral neuropathy was most frequently observed $(75 \%)$, followed by ILD $(62.5 \%)$, skin lesions (50\%), and glomerulonephritis and arthritis $(37.5 \%$ each). When organ lesions were compared between MPA groups with and without malignancies (Table 3), the group with malignancies developed peripheral neuropathy more frequently (75\% vs. $32.4 \%$; OR, 6.27; 95\% CI, $1.09-36.25 ; p=$ $0.045)$ and glomerulonephritis less frequently $(37.5 \%$ vs. $82.4 \%$; OR, 0.13 ; 95\% CI, $0.02-0.69$; $p=0.020$ ). Skin lesions were observed in $50 \%$ of cases, and there was no significant difference between MPA groups with and without malignancies $(26.5 \%$; OR, 2.78; 95\% CI, 0.57-12.51; $p$ value, 0.236; Table 3).

All cases with malignancies were positive for MPO-ANCA. For treatment of recently developed MPA cases with malignancies, corticosteroids were used in $87.5 \%$ of cases, and immunosuppressants were employed only in $37.5 \%$ (Table 2). With regard to surgical treatment of malignancies, all cases that had developed malignancy within the two years prior to the time of admission (Cases 1-4) had already been surgically treated before hospitalization. Meanwhile, only half of the cases that were diagnosed with malignancy upon admission (Cases 5-8) underwent surgery.

\section{Comparison of malignancy rates between control and MPA groups}

There were 126 RA cases (48 males and $78 \mathrm{fe}-$ males) in the control group with an average age of $70.1 \pm 9.3$ years upon admission and average disease duration of $170.6 \pm 379.8$ months. In the RA group, concurrent malignancies were observed in eight cases (four males and four females; $6.3 \%$ ) and the average

Table 2. Clinical Characteristics of MPA with Recently Developed Malignancies

\begin{tabular}{|c|c|c|c|c|c|c|c|c|c|}
\hline \multirow{2}{*}{ No. } & \multirow{2}{*}{$\operatorname{Sex}$} & \multirow{2}{*}{$\begin{array}{c}\text { Age } \\
\text { (years) }\end{array}$} & \multirow{2}{*}{$\begin{array}{c}\text { Duration of MPA } \\
\text { (months) }\end{array}$} & \multicolumn{2}{|c|}{ Malignant tumor } & \multirow{2}{*}{ Organ involvement } & \multicolumn{2}{|c|}{ ANCA } & \multirow{2}{*}{ Therapy } \\
\hline & & & & Type & Time of diagnosis & & MPO & PR-3 & \\
\hline 1 & $\mathrm{M}$ & 73 & 0 & Liver cancer & $<2$ & ILD, GN & + & - & PSL40 mg \\
\hline 2 & $\mathrm{~F}$ & 78 & 0 & Lung cancer & $<2$ & PN, ILD, purpura, livedo reticularis, arthritis & + & - & PSL15 mg \\
\hline 3 & M & 69 & 4 & Colon cancer & $<2$ & PN, GN, purpura & + & - & PSL45 mg, IVCY \\
\hline 4 & $\mathrm{~F}$ & 65 & 10 & Basal cell cancer & $<2$ & ILD, arthritis & + & - & IVCY, AZA \\
\hline 5 & M & 67 & 56 & Rectal cancer & 0 & PN, GN, purpura & + & - & m-PSL pulse, IVCY \\
\hline 6 & M & 77 & 14 & Duodenal cancer & 0 & PN, ILD, arthritis & + & - & PSL30 mg \\
\hline 7 & $\mathrm{~F}$ & 74 & 0 & Breast cancer, Liver cancer & 0 & PN, ILD, purpura, blisters & + & - & PSL30 mg \\
\hline 8 & $\mathrm{~F}$ & 80 & 1 & Cervical cancer & 0 & PN, skin ulcers, livedo reticularis, hearing & + & - & PSL20 mg \\
\hline
\end{tabular}


Table 3. Comparison of Organ Lesions in MPA Cases with and without Malignancies

\begin{tabular}{lcccccc}
\hline \multirow{2}{*}{ Organ involvement } & \multicolumn{2}{c}{ MPA [n (\%)] } & & \\
\cline { 2 - 3 } & $\begin{array}{c}\text { with malignancy } \\
(\mathrm{n}=8)\end{array}$ & $\begin{array}{c}\text { without malignancy } \\
(\mathrm{n}=34)\end{array}$ & & OR (95\% CI) & $p$-value* \\
\hline Glomerular nephritis & $3(37.5)$ & $28(82.4)$ & & 0.13 & $0.02-0.69$ & 0.020 \\
Interstitial lung disease & $5(62.5)$ & $22(64.7)$ & & 0.91 & $0.18-4.48$ & 1.000 \\
Arthritis & $3(37.5)$ & $15(44.1)$ & & 0.76 & $0.16-3.70$ & 1.000 \\
Peripheral neuropathy & $6(75.0)$ & $11(32.4)$ & & 6.27 & $1.09-36.25$ & 0.045 \\
Skin lesions & $4(50.0)$ & $9(26.5)$ & & 2.78 & $0.57-13.51$ & 0.236 \\
\hline
\end{tabular}

* $p$-value: Fisher's exact test

age was $71.3 \pm 6.4$ years. Concurrent malignancies included gastric cancer in two cases and one case each of lung cancer, colon cancer, renal cell carcinoma, prostate cancer, a colorectal carcinoid tumor, and skin basal cell carcinoma. Concurrent malignancies were diagnosed within two years before admission in two cases and on admission in six cases.

Rates of recently developed concurrent malignancies were compared between the MPA (19.0\%) and RA groups $(6.3 \%)$, and the MPA group concurrently developed malignancies significantly more often with an odds ratio of 3.47 (95\% CI: 1.21-9.93; $p$ $=0.029$; Fig. 1).

\section{Discussion}

In this study, we investigated the concurrence rate of recently developed malignancies with MPA cases newly admitted to the hospital and evaluated

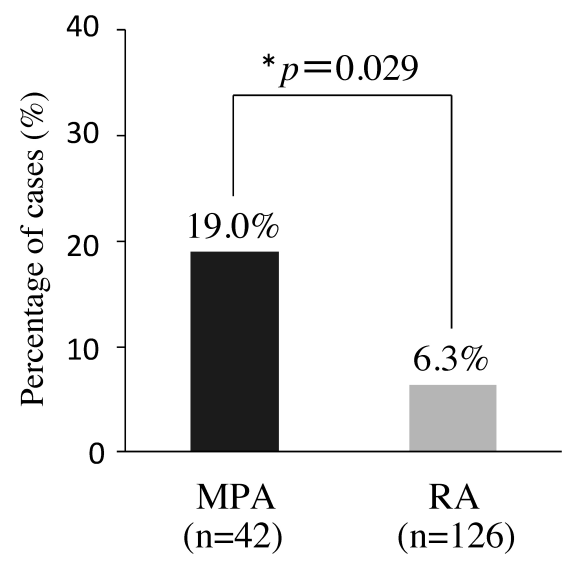

Figure 1. Comparison of concurrence rates of recently developed malignancies between MPA and RA cases. Odds ratio, 3.47 (95\%CI: 1.219.93).

*p-value: Fisher's exact test the clinical characteristics. Several large-scale studies demonstrated that cases with AAV developed malignancies 1.6-2.4 times as often as the general population $^{7-11)}$. Randomized controlled trials (RCTs) and long-term follow-up (LTFU) studies in Western countries showed that malignancies were observed in $12.6 \%$ of MPA cases and $10.8 \%$ in cases of granulomatosis with polyangiitis (GPA) during the 87-month follow-up period after treatment for vasculitis ${ }^{12) 18-211}$. Meanwhile, it was suggested that malignancies developed more frequently in vasculitis cases in which immunosuppressants were used to introduce remission and for maintenance therapy. Cyclophosphamide (CYC) has emerged as a major contributor to cancer development because of its direct carcinogenic properties. The most prominent cancers observed in AAV include urinary tract cancer, leukemia, and non-melanoma skin cancer ${ }^{(6) 713 / 22)}$. Faurschou et al. ${ }^{7)}$ reported that malignancies developed at a higher rate two years after the onset of treatment or when the cumulative CYC dose increased (CYC $>36 \mathrm{~g}$ ) in GPA cases. Most RCTs excluded cases with malignancies that developed before or at the start of the trial. Therefore, the concurrence rates of malignancies before and at the onset of AAV remain poorly understood $^{18-21)}$. In GPA cases, there has been no demonstrated increase of malignancies before the onset to within one year after the onset of vasculitis ${ }^{6 / 723)}$. Pankhurst et al. ${ }^{3)}$ reported in 2004 that concurrent malignancies were observed more frequently before the onset of vasculitis in MPA cases. According to their report, malignancies were concurrently observed in 14 of 122 MPA cases (11.5\%). Of those 14 cases, concurrent malignancies occurring within six months after MPA diagnosis were observed in only five cases, while in the nine remaining cases malignancies were observed at least three years prior to MPA diagnosis. In our study, recently developed malignancies were concurrently observed in as many as $9.5 \%$ of MPA cases by screening upon admission and in 
$19.0 \%$ of MPA cases when a two-year history was taken into consideration. While direct comparison was difficult due to design differences, our study showed a higher complication rate of malignancy in MPA patients than other studies ${ }^{3) 12(18-21)}$. It is presumed that active malignancy screening had a great impact in this study. Meanwhile, the average age was 69.9 years in MPA cases, a factor that may increase the concurrent rate of malignancies. Moreover, patients that had already received immunosuppressive treatment were included as subjects in this study, and it was impossible to rule out the influence of immunosuppressants on carcinogenesis in the nine MPA patients that had had disease for 25 months or more. We then matched the experimental conditions, including gender and age, and compared the concurrence rate of malignancies between the MPA and RA groups. Immunosuppressants, with methotrexate as the anchor drug, are also used for treatment of RA. In the Institute of Rheumatology, Rheumatoid Arthritis (IORRA) study, a large-scale cohort study on Japanese RA cases, Yamada et al. ${ }^{24)}$ reported that the concurrence rate of malignancies in Japanese RA cases were 1.18-fold higher than that of the general population (SIR1.18, [95\% CI, 1.02-1.37]). In our study, MPA cases developed malignancies 3.47 times as frequently as RA cases (Fig. 1). Taken together, MPA can be considered an autoimmune disease frequently accompanied by malignancies, and attention should be paid to latent malignancies.

For treatment of MPA patients with malignancy, immunosuppressants are occasionally used and moderate- to high-dose steroids are often administered to the control of vasculitis. Four MPA patients who had developed malignancy within two years before admission did not die within two years after hospitalization. Meanwhile, two patients who were diagnosed with malignancy on admission underwent surgery, and other two patients (50\%) died within two years after admission. The cause of death was malignancyrelated death. We suspect the reasons for the lower rate of surgical treatment may be cancer progression, delayed wound healing and increased susceptibility to infection by steroids, respiratory and renal dysfunction due to MPA, and increased risk due to old age.

Cancer-associated vasculitis is secondary vasculitis associated with malignancies and accounts for $0.4-4.2 \%$ of all vasculitis ${ }^{25-27}$. Cancer-associated vasculitis was categorized into vasculitis associated with probable etiology in the 2012 Revised International
Chapel Hill Consensus Conference ${ }^{28)}$, but an exact definition has yet to be established. In typical cases, hematopoietic malignancies such as myelodysplastic syndromes (MDS) are frequently observed, and vasculitis deteriorates as malignancies advance ${ }^{229-31}$. In addition, skin lesions such as purpura and ulcers were observed in $78.3 \%$ of cases and often exhibited leukocytoclastic vasculitis ${ }^{2}$. On the other hand, in this study, the concurrent malignancies observed were solid cancers, not hematopoietic cancers (Table 2). In our cases, none showed an improvement in vasculitis by cancer treatment alone. When characterizing organ lesions, peripheral neuropathy was often observed and glomerulonephritis was less frequently recognized. Skin lesions were observed in half of cases with malignancies. There was no significant difference in the frequency of skin lesions between cases with and without malignancy, though the results may be attributable to the small number of cases. Most cases with cancer-associated vasculitis predominantly developed skin lesions and leukocytoclastic vasculitis was recognized histologically'). Thus, the pathogenesis may be similar to cutaneous leukocytoclastic angiitis or cutaneous arteritis. Meanwhile, in this study all MPA cases that recently developed malignancy were positive for MPO-ANCA and showed pauci-immune vasculitis immunohistologically with various organ injuries from AAV. Therefore, it is considered that the etiology, pathogenesis, and clinical manifestations were different between the two groups.

Cancer has been linked with AAV as a potential cause or as a disease-triggering factor ${ }^{26) 31}$. Though inflammatory responses provoked by the underlying neoplasm contribute to the pathogenesis of vasculitis $^{26(629) 32)}$, the mechanisms contributing to the development of MPA with malignancies is poorly understood. Further studies are required to clarify the mechanisms underlying the development of malignancy and vasculitis.

\section{Conclusion}

In this study, MPA frequently accompanied malignancies of solid cancer. Peripheral neuropathy was observed frequently, but glomerulonephritis less frequently. Because malignancies occurred in up to $20 \%$ of MPA cases, those admitted for MPA should be thoroughly screened for malignancies. In Asian countries, no study has investigated complication rates of malignancy in cases with MPA using a large number of cases. Therefore, further study of similar cases is 
warranted.

\section{Acknowledgments}

We would like to thank our colleagues in the $\mathrm{Di}$ vision of Rheumatology and Allergy, Department of Internal Medicine, St. Marianna University School of Medicine. We also thank Dr. Yoichi Ichikawa, honorary director of St. Joseph Hospital, and Dr. Takashi Yasuda from the Department of Nephrology and Hypertension, Internal Medicine at Yokohama Seibu Hospital, St. Marianna University School of Medicine.

\section{Conflict of interest: none.}

\section{References}

1) Sigurgeirsson B, Lindelöf B, Edhag $O$, Allander E. Risk of cancer in patients with dermatomyositis or polymyositis. A population-based study. N Engl J Med 1992; 326: 363-367.

2) Fain $O$, Hamidou $M$, Cacoub $P$, Godeau $B$, Wechsler B, Pariès J, Stirnemann J, Morin AS, Gatfosse M, Hanslik T, Belmatoug N, Blétry O, Cevallos R, Delevaux I, Fisher E, Hayem G, Kaplan G, Le Hello C, Mouthon L, Larroche C, Lemaire V, Piette AM, Piette JC, Ponge T, Puechal X, Rossert J, Sarrot-Reynauld F, Sicard D, Ziza JM, Kahn MF, Guillevin L. Vasculitides associated with malignancies: analysis of sixty patients. Arthritis Rheum 2007; 57: 1473-1480.

3) Pankhurst T, Savage CO, Gordon C, Harper L. Malignancy is increased in ANCA-associated vasculitis. Rheumatology (Oxford) 2004; 43: 1532-1535.

4) Knight A, Askling J, Granath F, Sparen P, Ekbom A. Urinary bladder cancer in Wegener's granulomatosis: risks and relation to cyclophosphamide. Ann Rheum Dis 2004; 63: 1307-1311.

5) Tatsis E, Reinhold-Keller E, Steindorf K, Feller AC, Gross WL. Wegener's granulomatosis associated with renal cell carcinoma. Arthritis Rheum 1999; 42: 751-756.

6) Mahr A, Heijl C, Le Guenno G, Faurschou M. ANCA-associated vasculitis and malignancy: Current evidence for cause and consequence relationships. Best Pract Res Clin Rheumatol 2013; 27: 45-56.

7) Faurschou M, Sorensen IJ, Mellemkjaer L, Loft AG, Thomsen BS, Tvede N, Baslund B. Malignancies in Wegener's granulomatosis: incidence and relation to cyclophosphamide therapy in a cohort of 293 patients. J Rheumatol 2008; 35: 100-105.

8) Hoffman GS, Kerr GS, Leavitt RY, Hallahan CW, Lebovics RS, Travis WD, Rottem M, Fauci AS. Wegener granulomatosis: an analysis of 158 patients. Ann Intern Med 1992; 116: 488-498.

9) Knight A, Askling J, Ekbom A. Cancer incidence in a population-based cohort of patients with Wegener's granulomatosis. Int $\mathrm{J}$ Cancer 2002; 100: 82-85.

10) Westman KW, Bygren PG, Olsson H, Ranstam J, Wieslander J. Relapse rate, renal survival, and cancer morbidity in patients with Wegener's granulomatosis or microscopic polyangiitis with renal involvement. J Am Soc Nephrol 1998; 9: 842-852.

11) Heijl C, Harper L, Flossmann O, Stücker I, Scott DG, Watts RA, Höglund P, Westman K, Mahr A; European Vasculitis Study Group (EUVAS). Incidence of malignancy in patients treated for antineutrophil cytoplasm antibody-associated vasculitis: follow-up data from European Vasculitis Study Group clinical trials. Ann Rheum Dis 2011; 70: 1415-1421.

12) Robson J, Doll H, Suppiah R, Flossmann O, Harper L, Höglund P, Jayne D, Mahr A, Westman K, Luqmani R. Damage in the anca-associated vasculitides: long-term data from the European Vasculitis Study group (EUVAS) therapeutic trials. Ann Rheum Dis 2013; doi: 10.1136/annrheumdis-2013-203927. [Epub ahead of print]

13) Talar-Williams C, Hijazi YM, Walther MM, Linehan WM, Hallahan CW, Lubensky I, Kerr GS, Hoffman GS, Fauci AS, Sneller MC. Cyclophosphamide-induced cystitis and bladder cancer in patients with Wegener granulomatosis. Ann Intern Med 1996; 124: 477-484.

14) Jennette JC, Falk RJ, Andrassy K, Bacon PA, Churg J, Gross WL, Hagen EC, Hoffman GS, Hunder GG, Kallenberg CG, et al. Nomenclature of systemic vasculitides. Proposal of an international consensus conference. Arthritis Rheum 1994; 37: 187-192.

15) Ozaki S. ANCA-associated vasculitis: diagnostic and therapeutic strategy. Allergol Int 2007; 56: 87-96.

16) Arnett FC, Edworthy SM, Bloch DA, McShane DJ, Fries JF, Cooper NS, Healey LA, Kaplan SR, Liang MH, Luthra HS, Medsger Jr TA, Mitchell DM, Neustadt DH, Pinals RS, Schaller 
JG, Sharp JT. Wilder RL, Hunder GG. The American Rheumatism Association 1987 revised criteria for the classification of rheumatoid arthritis. Arthritis Rheum 1988; 31: 315-324.

17) Azuma K, Yamada H, Ohkubo M, Yamasaki Y, Yamasaki M, Mizushima M, Ozaki S. Incidence and predictive factors for malignancies in 136 Japanese patients with dermatomyositis, polymyositis and clinically amyopathic dermatomyositis. Mod Rheumatol 2011; 21: 178-183.

18) Jayne $D$, Rasmussen N, Andrassy K, Bacon P, Tervaert JW, Dadoniené J, Ekstrand A, Gaskin G, Gregorini G, de Groot K, Gross W, Hagen EC, Mirapeix E, Pettersson E, Siegert C, Sinico A, Tesar V, Westman K, Pusey C; European Vasculitis Study Group. A randomized trial of maintenance therapy for vasculitis associated with antineutrophil cytoplasmic autoantibodies. N Engl J Med 2003; 349: 36-44.

19) De Groot K, Rasmussen N, Bacon PA, Tervaert JW, Feighery C, Gregorini G, Gross WL, Luqmani R, Jayne DR. Randomized trial of cyclophosphamide versus methotrexate for induction of remission in early systemic antineutrophil cytoplasmic antibody-associated vasculitis. Arthritis Rheum 2005; 52: 2461-2469.

20) Jayne DR, Gaskin G, Rasmussen N, Abramowicz D, Ferrario F, Guillevin L, Mirapeix E, Savage CO, Sinico RA, Stegeman CA, Westman KW, van der Woude FJ, de Lind van Wijngaarden RA, Pusey CD; European Vasculitis Study Group. Randomized trial of plasma exchange or high-dosage methylprednisolone as adjunctive therapy for severe renal vasculitis. J Am Soc Nephrol 2007; 18: 2180-2188.

21) de Groot K, Harper L, Jayne DR, Flores Suarez LF, Gregorini G, Gross WL, Luqmani R, Pusey CD, Rasmussen N, Sinico RA, Tesar V, Vanhille P, Westman K, Savage CO; EUVAS (European Vasculitis Study Group). Pulse versus daily oral cyclophosphamide for induction of remission in antineutrophil cytoplasmic antibody-associated vasculitis: a randomized trial. Ann Intern Med 2009; 150: 670-680.

22) Stillwell TJ, Benson RC Jr, DeRemee RA, McDonald TJ, Weiland LH. Cyclophosphamideinduced bladder toxicity in Wegener's granulomatosis. Arthritis Rheum 1988; 31: 465-470.

23) Faurschou M, Mellemkjaer L, Sorensen IJ, Thomsen BS, Dreyer L, Baslund B. Cancer pre- ceding Wegener's granulomatosis: a case-control study. Rheumatology (Oxford) 2009; 48: 421-424.

24) Yamada T, Nakajima A, Inoue E, Tanaka E, Taniguchi A, Momohara S, Yamanaka $\mathrm{H}$. Incidence of malignancy in Japanese patients with rheumatoid arthritis. Rheumatol Int. 2011; 31: 1487-1492.

25) García-Porrúa C, González-Gay MA. Cutaneous vasculitis as a paraneoplastic syndrome in adults. Arthritis Rheum 1998; 41: 1133-1135.

26) Hutson TE, Hoffman GS. Temporal concurrence of vasculitis and cancer: a report of 12 cases. Arthritis Care Res 2000; 13: 417-423.

27) Blanco R, Martínez-Taboada VM, RodríguezValverde V, García-Fuentes M. Cutaneous vasculitis in children and adults. Associated diseases and etiologic factors in 303 patients. Medicine (Baltimore) 1998; 77: 403-418.

28) Jennette JC, Falk RJ, Bacon PA, Basu N, Cid MC, Ferrario F, Flores-Suarez LF, Gross WL, Guillevin L, Hagen EC, Hoffman GS, Jayne DR, Kallenberg CG, Lamprecht P, Langford CA, Luqmani RA, Mahr AD, Matteson EL, Merkel PA, Ozen S, Pusey CD, Rasmussen N, Rees AJ, Scott DG, Specks U, Stone JH, Takahashi K, Watts RA. 2012 revised International Chapel Hill Consensus Conference Nomenclature of Vasculitides. Arthritis Rheum 2013; 65: 1-11.

29) Podjasek JO, Wetter DA, Pittelkow MR, Wada DA. Cutaneous small-vessel vasculitis associated with solid organ malignancies: the Mayo Clinic experience, 1996 to 2009. J Am Acad Dermatol 2012; 66: e55-e65.

30) Solans-Laqué R, Bosch-Gil JA, Pérez-Bocanegra C, Selva-O'Callaghan A, Simeón-Aznar CP, Vilardell-Tarres M. Paraneoplastic vasculitis in patients with solid tumors: report of 15 cases. J Rheumatol 2008; 35: 294-304.

31) Abe H, Momose $S$, Takeuchi T. Microscopic polyangitis complicating double carcinoma of the stomach and duodenum: improvement after the resection of these carcinomas. Rheumatol Int 2011; 31: 105-108.

32) Sánchez-Guerrero J, Gutiérrez-Ureña S, Vidaller A, Reyes E, Iglesias A, Alarcón-Segovia D. Vasculitis as a paraneoplastic syndrome. Report of 11 cases and review of the literature. J Rheumatol 1990; 17: 1458-1462. 